\title{
Measurement and Evaluation of Reliability, Availability and Maintainability of a Diesel Locomotive Engine
}

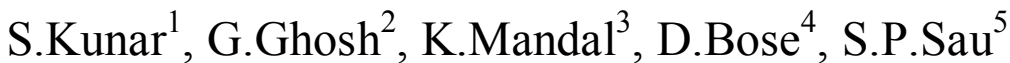 \\ ${ }^{1}$ Production Engineering, Jadavpur University, India \\ ${ }^{2,3,4}$ Mechanical Engineering \& ${ }^{5}$ Computer Science and Technology, NITTTR, India
}

\begin{abstract}
The growing complexity of equipments and systems often lead to failures and as a consequence the aspects of reliability, maintainability and availability have come into forefront. The failure of machineries and equipments causes disruption in production resulting from a loss of availability of the system and also increases the cost of maintenance. The present study deals with the determination of reliability and availability aspects of one of the significant constituent in a Railway Diesel Locomotive Engine. In order to assess the availability performance of these components, a broad set of studies has been carried out to gather accurate information at the level of detail considered suitable to meet the availability analysis target. The Reliability analysis is performed using the Weibull Distribution and the various data plots as well as failure rate information help in achieving results that may be utilized in the near future by the Railway Locomotive Engines for reducing the unexpected breakdowns and will enhance the reliability and availability of the Engine. In this work, $A B C$ analysis has been used for the maintenance of spare parts inventory. Here, Power pack assemblies, Engine System are used to focus on the reliability, maintainability and availability aspects.
\end{abstract}

Keywords: Availability, ABC analysis, engine system, maintainability, power pack assemblies, reliability, Weibull Distribution.

\section{Introduction}

The Reliability of an item is the probability that the item will perform a specific function under specified operational and environmental conditions at end throughout a specified time [1].Reliability must have certain criteria. It depends on numerous factors, most of which are random. It is difficult to measure reliability since there is no instrument by means of which this may be done for particular equipment. The respective reliabilities of the various components of complex equipment depend on the technology of their production, the quality of materials used in their manufacture, the conditions or environment in which they operate and so on. In view of these considerations, the reliability of equipment is closely related to several uncertainty factors. The Quantitative study of uncertainty, therefore, forms the starting point for a quantitative analysis of reliability. The theory which deals with the study of uncertainty is the probability theory. The maintenance policy will cover issues regarding general repairs, repair or discard policies, emergency recorder policies, inventory control, provisioning of spares, etc. It is possible to define some of the maintenance policies in advance and take design decision accordingly. The process of designing involves decision regarding module size, test procedures, builtin-redundancies, and degree of automation, inspection intervals, special test equipment, and safety requirements and so on Availability is a performance criterion for repairable systems that accounts for both the reliability and maintainability properties of a component or system. $\mathrm{ABC}$ analysis helps segregating the item from one another and fells how much valued the item is and controlling if to what extent is in the interest of the organization [2].

\section{Railway Diesel Locomotive Engine and its Components}

The following fig 1 shows a Railway Diesel Locomotive Engine. The engine is of ' $\mathrm{V}$ ' design, and is manufactured in 16 cylinders. The cylinders are arranged into pairs of cylinders, each pair using a common throw on the crankshaft. The cylinders are divided into two banks, left and right. 


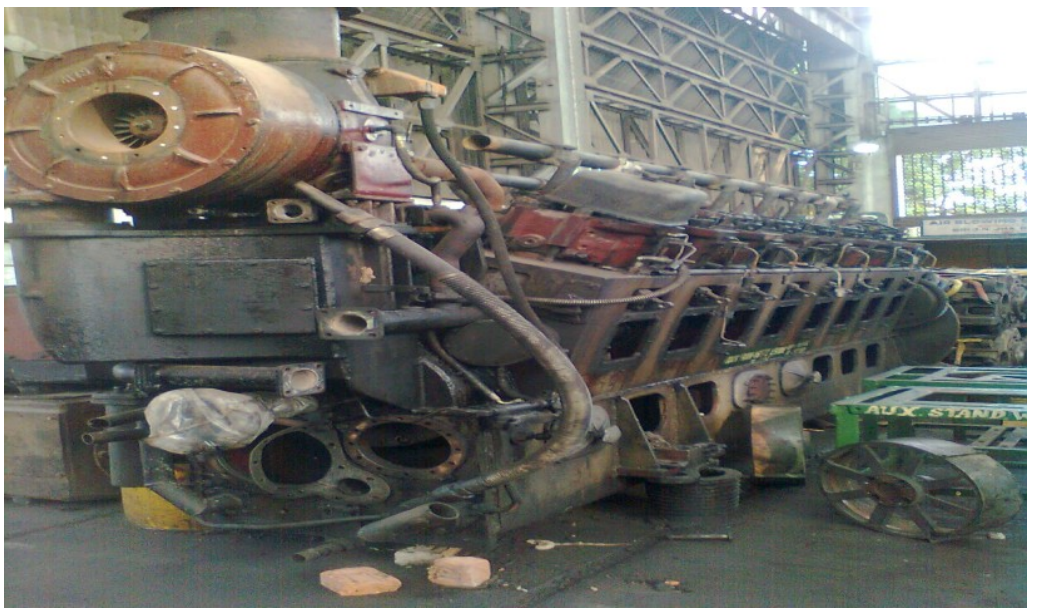

Figure1. Railway Diesel Locomotive Engine.

A Railway Diesel Locomotive Engine has the following main sub-systems.

1. Power pack assemblies

2. Engine System

\section{Failure}

Failure is any event that impacts a system in a way that adversely affects the system criteria. For example, the criteria could include output in a sold-out condition, or maintenance cost or capital resources in a constrained budget cycle, environmental excursions or safety, etc. A failure definition should contain specific criteria and not be ambiguous. Failure definition can change on a given system over time.

Field failures do not generally occur at a uniform rate, but follow a distribution in time commonly describe as a "bathtub curve." The life of a device can be divided into three regions: Infant Mortality Period, where the failure rate progressively improves; Useful Life Period, where the failure rate remains constant; and Wear out Period, where failure rates begin to increase. Within a population of units is a small sub-group of units with latent defects that will fail when exposed to a stress that would otherwise be benign to a good unit. With the failure of the weak units, the remaining population is more reliable, and the failure rate is known to decrease. Units that pass the Infant Mortality Period have a high probability of surviving the conditions provided by the system and its environment. Failures that occur during the Useful Life Period are residual defects surviving Infant Mortality, unpredictable system or environmental conditions, or premature wear out.

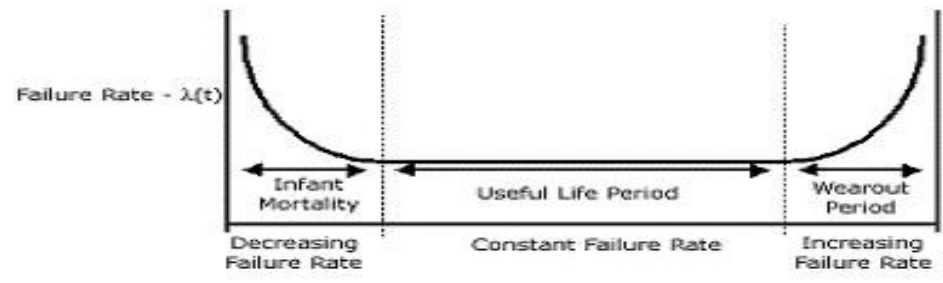

Figure 2. Bath-tub curve describing failure rates at different periods of life

\subsection{Reliabılıty Predictıon}

A reliability prediction is simply the analysis of parts and components which effort to predict and calculate the rate at which an item will fail. A reliability prediction is one of the most common forms of reliability analyses for calculating failure rate and MTBF, MTTR, Availability etc [3].

\subsubsection{Mean Time to Failure (MTTF)}

It is the expected value of time $t$ or the mean of the TTF (Time to Failure) distribution when one item is put into operation [4]

When and only when failure rate is a constant or $\lambda=\lambda(t)$ then

$$
M T T F=\int_{0}^{\infty} R(t) d T=\int_{0}^{\infty} e^{-\lambda t} d T=\frac{1}{\lambda}
$$




\subsubsection{Mean Time between Failures (MTBF)}

It is the expected average time between failure events that cause the item to go down. Therefore MTBF can be defined as the average time (generally expressed in hours) that a component works without failure If and only if the item has constant failure rate then,

\subsection{Failure Distribution}

$$
M T B F=\int_{0}^{\infty} R(t) d T=\frac{1}{\lambda}
$$

The goal of system modeling is to provide quantitative forecasts of various system performance measures such as downtime, availability, and number of failures, capacity, and cost. Evaluation of these measures is important to make optimal decisions when designing a system to either minimize overall cost or maximize a system performance measure within the allowable budget and other performance-based constraints.

Two important factors taken into account in the analysis of a system are the failure and repair behaviors of the system components. The failure and repair rates of components are often defined in terms of distributions, or how the failures and repairs occur during the time period the system is operational. Therefore, selecting the appropriate distributions for these failure and repair times is critical to analyze system metrics accurately.

A useful way to easily visualize the characteristics of a failure or repair distribution is through the use of Probability Density Functions (PDF) [5]. In general, the shape or type of failure distribution depends upon the component's failure mechanisms. Similarly, the shape or type of repair distribution depends upon several factors associated with component repairs. Several methods are used to determine the distribution that best fits a given failure or repair pattern. Or, if failures or repairs are known to follow a particular distribution, the specific parameters that define this pattern can be determined by using the known failure and repair times.

If the type of distribution is not known in advance, then the distribution that best fits the failure or repair times can be found using statistical methods. To find the best distribution manually, probability plot papers are used. Alternatively, engineering software products can also be used to generate probability plots and determine best-fit distributions. In general, it is better to use available software tools because best-fit distributions are determined using scientific analysis rather than human judgment, which must be used when manually creating probability plots. Such engineering software products are commonly referred to as "Weibull" analysis tools, simply because Weibull is a widely accepted, commonly used distribution for describing failure and repair rates.

Determining the failure and repair distributions of a system and its components is a significant part of evaluating the reliability of the design. Distributions may be referred to as single-parameter or two-parameter distributions. For single-parameter distributions, only one variable is used to define the shape of the curve. Two-parameter distributions require two variables to accurately model the distribution.

\subsection{Collection of Data}

The most essential precondition for reliability and failure analysis or maintenance planning is the availability of relevant data. For the present analysis, data related to Railway Diesel Locomotive Engine, its Mechanical system and Electrical system failures during last five years [2007 January to 2011 December] are collected. The database includes no. of breakdowns related to different types of systems or components failures of Diesel Locomotive Engine and their monthly or year wise available No. of failure of a component or system, cause of failure and corrective action taken previously.

The documentation of failure data (table 1 and fig.3) on Diesel Locomotive Engine, daily breakdown record has been collected from the daily maintenance statistics lab in the DEISEL SHED.

Table 1. No. of Failures of different components

\begin{tabular}{|c|c|c|}
\hline SI. No. & Name of Different Components & No. of Failures \\
\hline 01 & Power pack assemblies & 10 \\
\hline 02 & Engine system failure & 06 \\
\hline
\end{tabular}




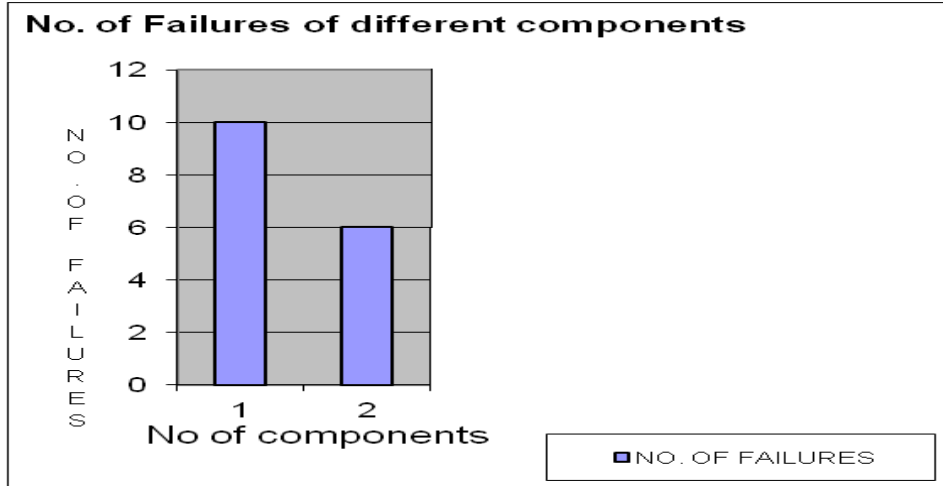

Figure 3. No. of Failures of different components

\subsection{Failures of Power pack assemblies}

Fig.4 shows the different failure zones of power pack assemblies. It has been observed that maximum failure occurs at Cam shaft joint flange broken and thread warm out.

broken

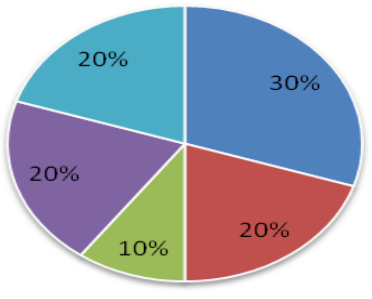

Figure 4. Failures of Power pack assemblies

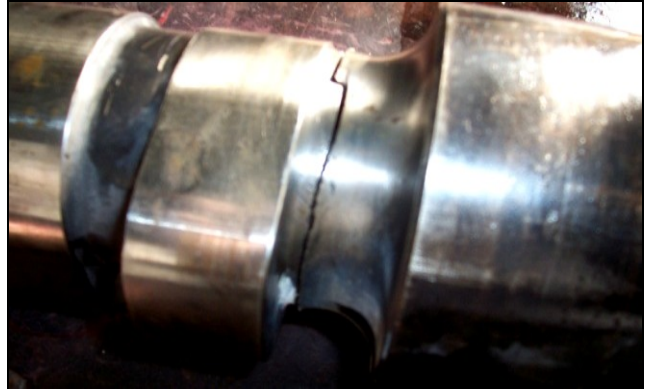

Figure 5. Cam shaft joint flange

1. Cam shaft joint flange broken and thread warm out refer fig.5.

2. Cylinder head crack.

3. Extension shaft $2^{\text {nd }}$ coupling ratter pad damage.

4. Cylinder head valve broken refer fig.6.

5. Cylinder head dummy plug thrown out.

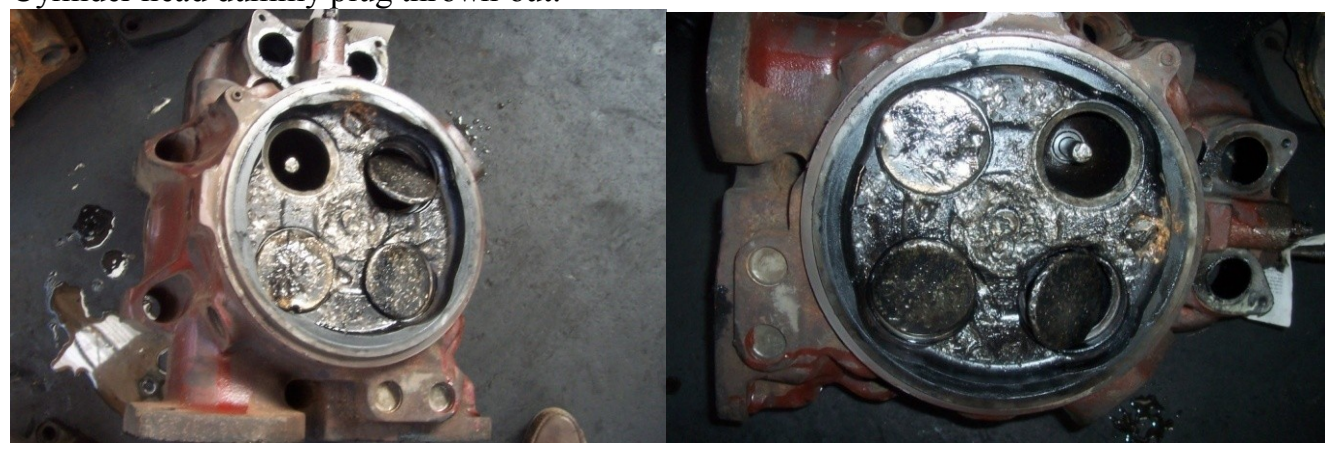

Figure 6. Cylinder head valve broken

\subsection{Failures of Engine system}

From survey it has been observed that the flexible hose burst, piston ring broken and H.P tube damage each comprises as well as 33\% refer fig. 7 .

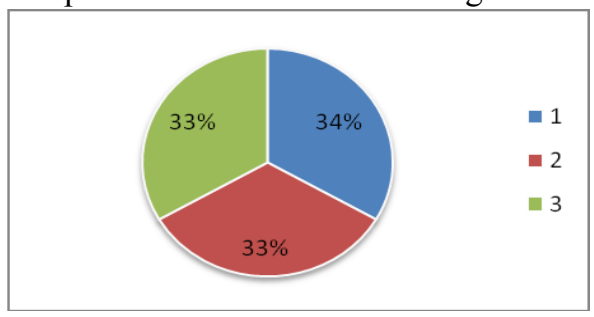

Figure.7 Failures of Engine system

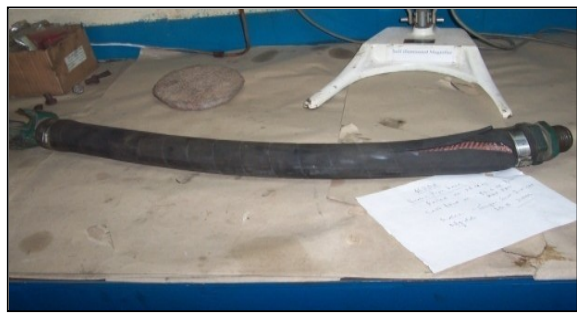

Figure. 8 Flexible hose burst

1. Flexible hose burst. (A/Cooler) refer fig.8. 
2. Piston ring broken refers fig. 9 \& 10 .

3. HP tube crack

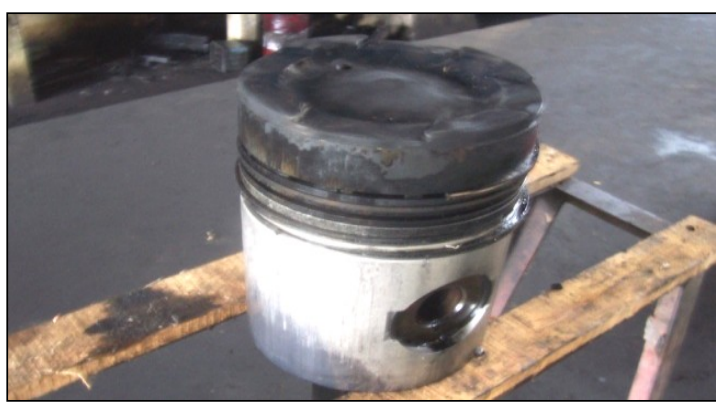

Figure 9. Piston ring broken

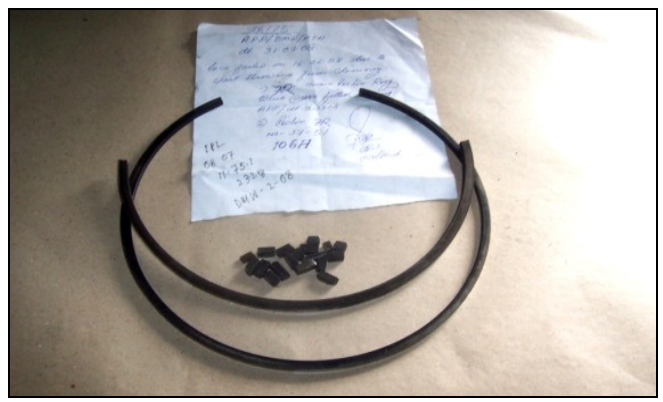

Figure10. Piston ring broken

\section{Reliability Analysis}

The Locomotive Engine under investigation is composed three components. The components are Power pack assemblies, Engine system.

\subsection{Hazard Model \& Probability Distribution}

The initial stage of reliability analysis is to predict the hazard model of the failures and to choose a distribution among various probability distributions like Normal distribution, Exponential distribution, Poison distribution, Weibull distribution etc. The probability distributions are grouped as follows:

- Hazard model with constant failure rate can be followed by normal, exponential distributions.

- Hazard model with increasing or decreasing failure rates can be followed by Weibull distribution.

\subsection{Graphical Evaluation for Reliability Prediction}

There are generally two ways for graphical evaluation visualizes -Exponential plot and Weibull Plot. When the failure rate is constant, the distribution follows exponential probability law and when failure rate is not constant i.e. non-linear hazard model follows Weibull distribution.

\subsection{Linear Regression Analysis: Selection of Distribution}

The observed data regarding the failures of different components of the Railway Diesel Locomotive Engine shows that the failure rates of the components are not constant. So the Weibull distribution model can be adopted. Moreover the technique of linear regression analysis confirms the suitability to use Weibull distribution for the different components of the Railway Diesel Locomotive Engine. The analysis determines the best-fit line in the least square sense. The least square test has been performed to obtain the increasing/decreasing rate of failures [6].

Linear regression analysis has been carried out by using the Probability equation.

$$
R_{x, f(x)}=\frac{\sum[x f(x)]-\frac{\left(\sum x\right)\left[\sum f(x)\right]}{N}}{\sqrt{\left[\sum\left(x^{2}\right)-\frac{\left(\sum x\right)^{2}}{N}\right]\left[\sum f\left(x^{2}\right)-\frac{\sum f(x)^{2}}{N}\right]}}
$$

Where,

$\mathrm{X}=$ Breakdown hours

$\mathrm{Y}=\mathrm{f}(\mathrm{x})=$ Cumulative $\%$ failures

$\mathrm{N}=$ number of trials

$\mathrm{R}_{\mathrm{x}, \mathrm{f}(\mathrm{x})}=$ Correlation coefficient

Failure data of the different components of the Diesel Locomotive Engine is used for determining the correlation co-efficient (Table 1). From the concept of probability, we know that the correlation coefficient must be in between -1.0 to +1.0 . If the correlation coefficient is positive, then the failure rate is increasing, otherwise the rate is decreasing. The correlation coefficients of the different components of the Railway Diesel Locomotive Engine under study shows increasing rate of failures. Weibull distribution can be applied for the estimation of reliability of the different components of the Railway Diesel Locomotive Engine. 
Table 2: Correlation Coefficient

\begin{tabular}{|c|c|}
\hline Name of Components & Correlation Coefficient \\
\hline Power Pack Assemblies & 0.796 \\
\hline Engine System & 0.779 \\
\hline
\end{tabular}

\subsection{Weibull Distribution}

About all the distributions available for reliability calculations, the Weibull distribution [7] is the only unique to the field. Allodia Weibull (1887-1979) pointed out that normal distributions are not applicable for characterizing initial metallurgical strengths during his study on metallurgical failures. He then introduced a function that could embrace a great variety of distributions and used seven different case studies to demonstrate how this function allowed the data to select the most appropriate distribution from a broad family of Weibull distributions. Probably the most widely used distribution in reliability engineering, the Weibull distribution can model failures caused by fatigue, corrosion, mechanical abrasion, diffusion and other degradation processes.

The two parameter Weibull distribution requires characteristic life $(\eta)$ and shape factor $(\beta)$ values. Beta $(\beta)$ determines the shape of the distribution. If $\beta$ is greater than 1 , the failure rate is increasing. If $\beta$ is less than 1 , the failure rate is decreasing. If $\beta$ is equal to 1 , the failure rate is constant. There are several ways to check whether data follows a Weibull distribution, the best choice is to use a Weibull analysis software product. If such a tool is not available, data can be manually plotted on a Weibull probability plot to determine if it follows a straight line. A straight line on the probability plot indicates that the data is following a Weibull distribution.

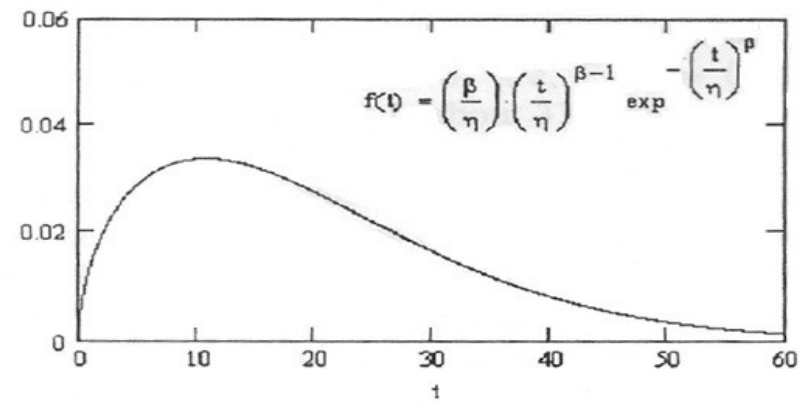

Figure 11. Weibull Distribution

Reliability analysis of the selected components of the Railway Locomotive Engine has been carried out with due consideration of failure as an indication of the underlying cause of failure has been summarized in term of Weibull shape parameter. Weibull shape parameter $\beta$ also indicates whether the failure rate is constant or increasing or decreasing if $\beta=1.0, \beta>1.0, \beta<1.0$ respectively. The cumulative $\%$ failures versus operating time data are plotted on Weibull graph [Fig.12 \& 13] and the values of the parameters are obtained using the statistical software 'MINITAB15.

Table 3: Weibull plot for Power pack assemblies

\begin{tabular}{|c|c|c|c|c|c|}
\hline $\begin{array}{c}\text { SL. } \\
\text { NO }\end{array}$ & MONTH & $\begin{array}{c}\text { MONTHLY } \\
\text { OPERATING } \\
\text { TIME(HOURS) }\end{array}$ & $\begin{array}{c}\text { NO OF } \\
\text { FAILURES }\end{array}$ & $\begin{array}{c}\text { PERCENTAGE } \\
\text { FAILURES }\end{array}$ & $\begin{array}{c}\text { CUMULATIVE } \\
\text { \% FAILURES }\end{array}$ \\
\hline 1 & January'07 & 720 & 0 & 0 & 0 \\
\hline 2 & & 620 & 0 & 0 & 0 \\
\hline 3 & & 576 & 0 & 0 & 0 \\
\hline 4 & & 600 & 0 & 0 & 0 \\
\hline 5 & & 708 & 0 & 0 & 0 \\
\hline 6 & & 700 & 0 & 0 & 0 \\
\hline 7 & & 734 & 0 & 0 & 0 \\
\hline 8 & & 734 & 0 & 0 & 0 \\
\hline 9 & & 648 & 0 & 0 & 0 \\
\hline 10 & & 734 & 0 & 0 & 0 \\
\hline 11 & & 672 & 0 & 0 & 10 \\
\hline 12 & & 670 & 0 & 0 & 0 \\
\hline 13 & January'08 & 724 & 0 & 0 & 0 \\
\hline 14 & & 686 & 1 & & 0 \\
\hline
\end{tabular}




\begin{tabular}{|c|c|c|c|c|c|}
\hline 15 & & 732 & 0 & 0 & 10 \\
\hline 16 & & 638 & 0 & 0 & 10 \\
\hline 17 & & 734 & 0 & 0 & 10 \\
\hline 18 & & 710 & 0 & 0 & 10 \\
\hline 19 & & 660 & 0 & 0 & 10 \\
\hline 20 & & 710 & 0 & 0 & 10 \\
\hline 21 & & 708 & 1 & 10 & 20 \\
\hline 22 & & 744 & 0 & 0 & 20 \\
\hline 23 & & 624 & 0 & 0 & 20 \\
\hline 24 & & 734 & 0 & 0 & 20 \\
\hline 25 & January'09 & 696 & 0 & 0 & 20 \\
\hline 26 & & 600 & 0 & 0 & 20 \\
\hline 27 & & 733 & 0 & 0 & 20 \\
\hline 28 & & 708 & 0 & 0 & 20 \\
\hline 29 & & 720 & 3 & 30 & 50 \\
\hline 30 & & 696 & 0 & 0 & 50 \\
\hline 31 & & 734 & 0 & 0 & 50 \\
\hline 32 & & 718 & 0 & 0 & 50 \\
\hline 33 & & 710 & 0 & 0 & 50 \\
\hline 34 & & 672 & 0 & 0 & 50 \\
\hline 35 & & 710 & 0 & 0 & 50 \\
\hline 36 & & 744 & 1 & 10 & 60 \\
\hline 37 & January'10 & 600 & 2 & 20 & 80 \\
\hline 38 & & 600 & 0 & 0 & 80 \\
\hline 39 & & 720 & 0 & 0 & 80 \\
\hline 40 & & 576 & 0 & 0 & 80 \\
\hline 41 & & 744 & 0 & 0 & 80 \\
\hline 42 & & 696 & 0 & 0 & 80 \\
\hline 43 & & 600 & 0 & 0 & 80 \\
\hline 44 & & 720 & 0 & 0 & 80 \\
\hline 45 & & 720 & 0 & 0 & 80 \\
\hline 46 & & 696 & 0 & 0 & 80 \\
\hline 47 & & 672 & 0 & 0 & 80 \\
\hline 48 & & 734 & 0 & 0 & 80 \\
\hline 49 & January'11 & 732 & 0 & 0 & 80 \\
\hline 50 & & 576 & 0 & 0 & 80 \\
\hline 51 & & 144 & 2 & 20 & 100 \\
\hline 52 & & 552 & 0 & 0 & 100 \\
\hline 53 & & 504 & 0 & 0 & 100 \\
\hline 54 & & 648 & 0 & 0 & 100 \\
\hline 55 & & 720 & 0 & 0 & 100 \\
\hline 56 & & 696 & 0 & 0 & 100 \\
\hline 57 & & 600 & 0 & 0 & 100 \\
\hline 58 & & 600 & 0 & 0 & 100 \\
\hline 59 & & 648 & 0 & 0 & 100 \\
\hline 60 & & 732 & 0 & 0 & 100 \\
\hline
\end{tabular}

Table 4: Weibull plot for Engine system

\begin{tabular}{|c|c|c|c|c|c|}
\hline $\begin{array}{c}\text { SL. } \\
\text { NO }\end{array}$ & MONTH & $\begin{array}{c}\text { MONTHLY } \\
\text { OPERATING } \\
\text { TIME(HOURS) }\end{array}$ & $\begin{array}{c}\text { NO OF } \\
\text { FAILURES }\end{array}$ & $\begin{array}{c}\text { PERCENTAGE } \\
\text { FAILURES }\end{array}$ & $\begin{array}{c}\text { CUMULATIVE } \\
\% \text { FAILURES }\end{array}$ \\
\hline 1 & January'07 & 720 & 0 & 0 & 0 \\
\hline 2 & & 620 & 0 & 0 & 0 \\
\hline 3 & & 576 & 0 & 0 & 0 \\
\hline 4 & & 600 & 1 & 16.667 & 16.667 \\
\hline 5 & & 708 & 0 & 0 & 16.667 \\
\hline
\end{tabular}


Measurement and Evaluation of Reliability, Availability and Maintainability of a Diesel Locomotive

\begin{tabular}{|c|c|c|c|c|c|}
\hline 6 & & 700 & 1 & 16.667 & 33.333 \\
\hline 7 & & 734 & 0 & 0 & 33.333 \\
\hline 8 & & 734 & 0 & 0 & 33.333 \\
\hline 9 & & 648 & 0 & 0 & 33.332 \\
\hline 10 & & 734 & 0 & 0 & 33.332 \\
\hline 11 & & 672 & 0 & 0 & 33.332 \\
\hline 12 & & 670 & 0 & 0 & 33.332 \\
\hline 13 & January'08 & 724 & 0 & 0 & 33.332 \\
\hline 14 & & 686 & 0 & 0 & 33.332 \\
\hline 15 & & 732 & 0 & 0 & 33.332 \\
\hline 16 & & 638 & 0 & 0 & 33.332 \\
\hline 17 & & 734 & 0 & 0 & 33.332 \\
\hline 18 & & 710 & 0 & 0 & 33.332 \\
\hline 19 & & 660 & 0 & 0 & 33.332 \\
\hline 20 & & 710 & 0 & 0 & 33.332 \\
\hline 21 & & 708 & 0 & 0 & 33.332 \\
\hline 22 & & 744 & 0 & 0 & 33.332 \\
\hline 23 & & 624 & 0 & 0 & 33.332 \\
\hline 24 & & 734 & 0 & 0 & 33.332 \\
\hline 25 & January'09 & 696 & 0 & 0 & 33.332 \\
\hline 26 & & 600 & 0 & 0 & 33.332 \\
\hline 27 & & 733 & 1 & 16.667 & 50 \\
\hline 28 & & 708 & 0 & 0 & 50 \\
\hline 29 & & 720 & 0 & 0 & 50 \\
\hline 30 & & 696 & 0 & 0 & 50 \\
\hline 31 & & 734 & 0 & 0 & 50 \\
\hline 32 & & 718 & 1 & 16.667 & 66.667 \\
\hline 33 & & 710 & 0 & 0 & 66.664 \\
\hline 34 & & 672 & 0 & 0 & 66.664 \\
\hline 35 & & 710 & 0 & 0 & 66.664 \\
\hline 36 & & 744 & 0 & 0 & 66.664 \\
\hline 37 & January'10 & 600 & 0 & 0 & 66.664 \\
\hline 38 & & 600 & 0 & 0 & 66.664 \\
\hline 39 & & 720 & 0 & 0 & 66.664 \\
\hline 40 & & 576 & 0 & 0 & 66.664 \\
\hline 41 & & 744 & 0 & 0 & 66.664 \\
\hline 42 & & 696 & 0 & 0 & 66.664 \\
\hline 43 & & 600 & 0 & 0 & 66.664 \\
\hline 44 & & 720 & 0 & 0 & 66.664 \\
\hline 45 & & 720 & 0 & 0 & 66.664 \\
\hline 46 & & 696 & 0 & 0 & 66.664 \\
\hline 47 & & 672 & 0 & 0 & 66.664 \\
\hline 48 & & 734 & 0 & 0 & 66.664 \\
\hline 49 & January'11 & 732 & 0 & 0 & 66.664 \\
\hline 50 & & 576 & 1 & 16.667 & 83.333 \\
\hline 51 & & 144 & 0 & 0 & 83.333 \\
\hline 52 & & 552 & 0 & 0 & 83.333 \\
\hline 53 & & 504 & 0 & 0 & 83.333 \\
\hline 54 & & 648 & 0 & 0 & 83.333 \\
\hline 55 & & 720 & 0 & 0 & 83.333 \\
\hline 56 & & 696 & 0 & 0 & 83.333 \\
\hline 57 & & 600 & 0 & 0 & 83.333 \\
\hline 58 & & 600 & 1 & 16.667 & 100 \\
\hline 59 & & 648 & 0 & 0 & 100 \\
\hline 60 & & 732 & 0 & 0 & 100 \\
\hline
\end{tabular}




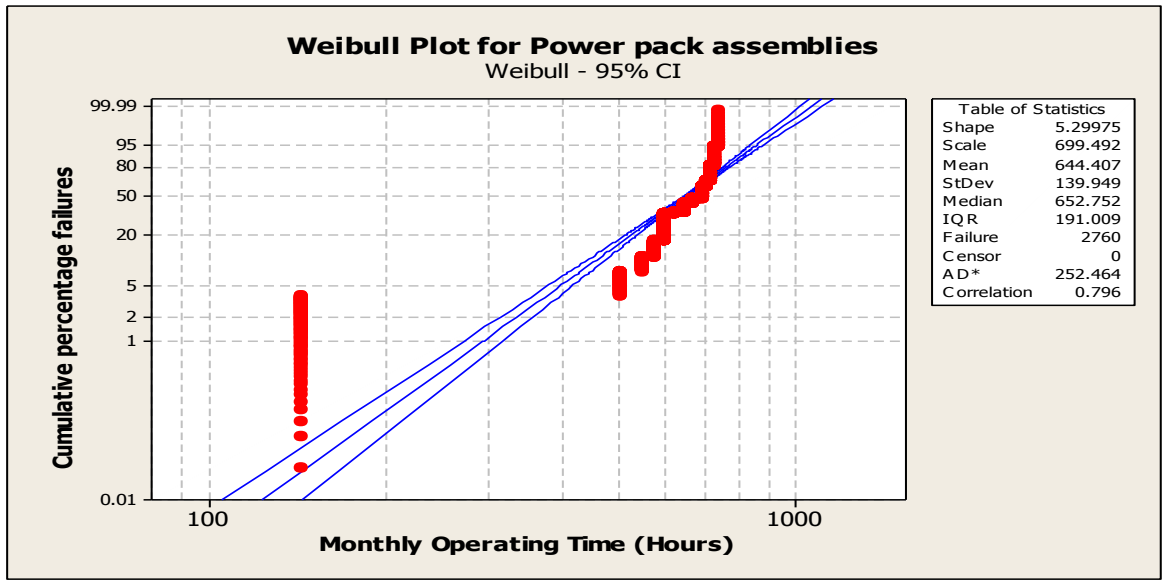

Figure 12. Weibull plot for Power pack assemblies

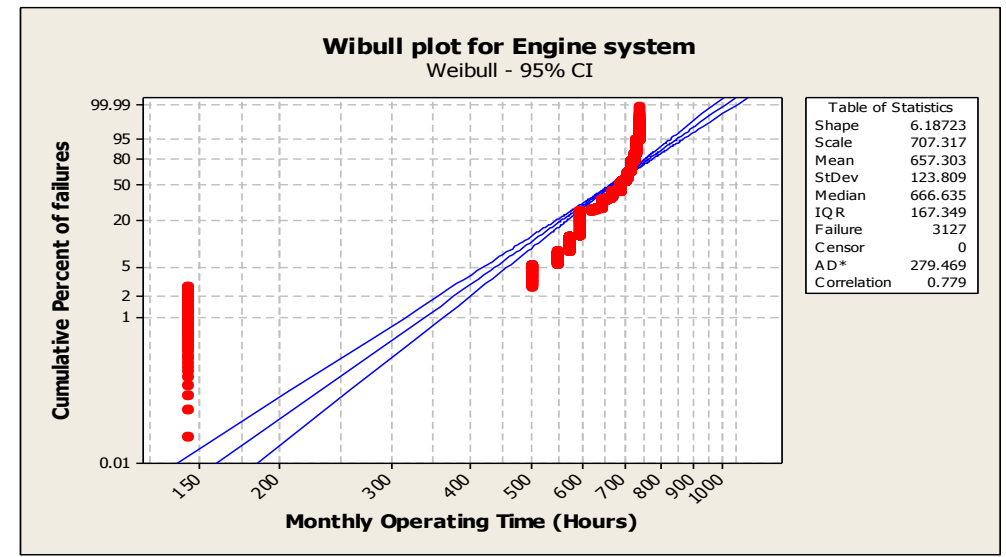

Figure 13. Weibull plot for Engine system

\section{Availability Analysis}

Availability is a performance criterion for repairable system or any normal system that accounts for both the reliability and maintainability properties of a component of a system is operating properly when it is required to use. As a matter of fact availability is the probability that a system is not failed or undergoing a repair action / maintenance job when it needs to be used. So the estimation of availability plays vital role of both reliability and maintainability aspects are considered for a system or components under investigation.

\subsection{Availability}

Availability is a performance criterion for repairable systems that accounts for both the reliability and maintainability properties of a component or system. It is defined as the probability that the system is operating properly when it is requested for use. That is availability is the probability that a system is not failed or undergoing repair action when it needs to be used [2].

$$
\mathrm{A}_{\mathrm{IN}}=\mathrm{MTBF} /(\mathrm{MTBF}+\mathrm{MTTR})
$$

It is possible to define three types of availability depending on the time elements we consider.

\subsubsection{Inherent Availability}

This is a probability that a system or equipment shall operate satisfactorily when used under stated conditions in an ideal support environment, without consideration for any scheduled or preventive maintenance at any given time. Mathematically it is expressed [2] as

$$
\mathrm{A}_{\mathrm{IN}}=\mathrm{MTBF} /(\mathrm{MTBF}+\mathrm{MTTR})
$$

\subsubsection{Achieved Availability}

This is a probability that a system or equipment shall operate satisfactorily when used under stated conditions in an ideal support environment at any given time. It may be expressed as [2]

$$
\mathrm{A}_{\mathrm{a}}=\mathrm{MTBM} /(\mathrm{MTBM}+\mathrm{MDT})
$$


Where, MTBM is the mean active-maintenance down time resulting from both preventive and corrective maintenance.

\subsubsection{Operational Availability}

In any real operation, we cannot reduce administrative down time and supply downtime to zero. A certain amount of delay will always be caused by time elements such as these and if they are taken into account then we obtain the operational availability. It may be defined as the probability that a system or equipment shall operate satisfactorily when used under stated conditions and in an actual supply environment at any given time. It may be expressed [2] as

$$
\mathrm{A}_{\mathrm{OP}}=\mathrm{MTBF} /(\mathrm{MTBF}+\mathrm{MDT})
$$

In general the availability of a system is a complex function of reliability maintainability and supply effectiveness. This can be expressed as

$$
\mathrm{As}=\mathrm{f}(\mathrm{Rs}, \mathrm{Ms}, \mathrm{Ss})
$$

Where, As = System Availability, Ss = Supply Effectiveness, Rs= System Reliability, $\mathrm{Ms}=$ System Maintainability.

\begin{tabular}{|c|c|c|c|c|c|c|c|c|c|c|}
\hline $\begin{array}{c}\text { SL.N } \\
\text { O. }\end{array}$ & MONTH & $\begin{array}{c}\text { UPTI } \\
\text { ME } \\
\text { (HOU } \\
\text { RS) }\end{array}$ & $\begin{array}{c}\text { DOWNT } \\
\text { IME } \\
\text { (HOURS } \\
\text { ) }\end{array}$ & $\begin{array}{l}\text { NO. OF } \\
\text { FAILURE } \\
\quad \text { S }\end{array}$ & $\begin{array}{c}\text { MTB } \\
\text { F } \\
\text { (HO } \\
\text { URS) }\end{array}$ & $\begin{array}{c}\text { HAZA } \\
\text { RD } \\
\text { RATE }\end{array}$ & $\begin{array}{c}\text { MDT } \\
\text { (HOU } \\
\text { RS) }\end{array}$ & AOP & $\begin{array}{c}\text { MTTR } \\
\text { (HOU } \\
\text { RS) }\end{array}$ & AIN \\
\hline 1 & January'07 & 720 & 24 & 0 & & 0 & & 1 & & 1 \\
\hline 2 & & 620 & 12 & 0 & & 0 & & 1 & & 1 \\
\hline 3 & & 576 & 144 & 0 & & 0 & & 1 & & 1 \\
\hline 4 & & 600 & 120 & 0 & & 0 & & 1 & & 1 \\
\hline 5 & & 708 & 36 & 0 & & 0 & & 1 & & 1 \\
\hline 6 & & 700 & 20 & 0 & & 0 & & 1 & & 1 \\
\hline 7 & & 734 & 10 & 0 & & 0 & & 1 & & 1 \\
\hline 8 & & 734 & 10 & 0 & & 0 & & 1 & & 1 \\
\hline 9 & & 648 & 72 & 0 & & 0 & & 1 & & 1 \\
\hline 10 & & 734 & 10 & 0 & & 0 & & 1 & & 1 \\
\hline 11 & & 672 & 48 & 0 & & 0 & & 1 & & 1 \\
\hline 12 & & 670 & 24 & 0 & & 0 & & 1 & & 1 \\
\hline 13 & January'08 & 724 & 10 & 0 & & 0 & & 1 & & 1 \\
\hline 14 & & 686 & 10 & 1 & 686 & 0.00145 & 10 & 0.985 & 3 & 0.995 \\
\hline 15 & & 732 & 12 & 0 & & 0 & & 1 & & 1 \\
\hline 16 & & 638 & 82 & 0 & & 0 & & 1 & & 1 \\
\hline 17 & & 734 & 10 & 0 & & 0 & & 1 & & 1 \\
\hline 18 & & 710 & 10 & 0 & & 0 & & 1 & & 1 \\
\hline 19 & & 660 & 84 & 0 & & 0 & & 1 & & 1 \\
\hline 20 & & 710 & 10 & 0 & & 0 & & 1 & & 1 \\
\hline 21 & & 708 & 12 & 1 & 708 & 0.00141 & 12 & 0.983 & 3.6 & 0.983 \\
\hline 22 & & 744 & 0 & 0 & & 0 & & 1 & & 1 \\
\hline 23 & & 624 & 72 & 0 & & 0 & & 1 & & 1 \\
\hline 24 & & 734 & 10 & 0 & & 0 & & 1 & & 1 \\
\hline 25 & January'09 & 696 & 48 & 0 & & 0 & & 1 & & 1 \\
\hline 26 & & 600 & 72 & 0 & & 0 & & 1 & & 1 \\
\hline 27 & & 733 & 10 & 0 & & 0 & & 1 & & 1 \\
\hline 28 & & 708 & 12 & 0 & & 0 & & 1 & & 1 \\
\hline 29 & & 720 & 0 & 3 & 240 & 0.00416 & 0 & 1 & 0 & 1 \\
\hline 30 & & 696 & 24 & 0 & & 0 & & 1 & & 1 \\
\hline 31 & & 734 & 10 & 0 & & 0 & & 1 & & 1 \\
\hline 32 & & 718 & 26 & 0 & & 0 & & 1 & & 1 \\
\hline 33 & & 710 & 10 & 0 & & 0 & & 1 & & 1 \\
\hline 34 & & 672 & 72 & 0 & & 0 & & 1 & & 1 \\
\hline 35 & & 710 & 10 & 0 & & 0 & & 1 & & 1 \\
\hline 36 & & 744 & 0 & 1 & 744 & 0.00134 & 0 & 1 & 0 & 1 \\
\hline 37 & January'10 & 600 & 120 & 2 & 300 & 0.00333 & 60 & 0.833 & 18 & 0.943 \\
\hline 38 & & 600 & 48 & 0 & & 0 & & 1 & & 1 \\
\hline 39 & & 720 & 24 & 0 & & 0 & & 1 & & 1 \\
\hline 40 & & 576 & 144 & 0 & & 0 & & 1 & & 1 \\
\hline
\end{tabular}

Table 5. Estimation of availability of Power Pack Assemblies 


\begin{tabular}{|l|l|l|l|l|l|l|l|l|l|l|}
\hline 41 & & 744 & 0 & 0 & & 0 & & 1 & 1 \\
\hline 42 & & 696 & 24 & 0 & & 0 & & 1 & & 1 \\
\hline 43 & & 600 & 120 & 0 & & 0 & & 1 & & 1 \\
\hline 44 & & 720 & 24 & 0 & & 0 & & 1 & & 1 \\
\hline 45 & & 720 & 24 & 0 & & 0 & & 1 & & 1 \\
\hline 46 & & 696 & 0 & 0 & & 0 & & 1 & & 1 \\
\hline 47 & & 672 & 24 & 0 & & 0 & & 1 & & 1 \\
\hline 48 & & 734 & 48 & 0 & & 0 & & 1 & & 1 \\
\hline 49 & January'11 & 732 & 12 & 0 & & 0 & & 1 & & 1 \\
\hline 50 & & 576 & 120 & 0 & & 0 & & 1 & & 1 \\
\hline 51 & & 144 & 192 & 2 & 72 & 0.01388 & 96 & 0.428 & 28.8 & 0.7142 \\
\hline 52 & & 552 & 168 & 0 & & 0 & & 1 & & 1 \\
\hline 53 & & 504 & 216 & 0 & & 0 & & 1 & & 1 \\
\hline 54 & & 648 & 72 & 0 & & 0 & & 1 & & 1 \\
\hline 55 & & 720 & 24 & 0 & & 0 & & 1 & & 1 \\
\hline 56 & & 696 & 48 & 0 & & 0 & & 1 & & 1 \\
\hline 57 & & 600 & 120 & 0 & & 0 & & 1 & & 1 \\
\hline 58 & & 600 & 120 & 0 & & 0 & & 1 & & 1 \\
\hline 59 & & 648 & 72 & 0 & & 0 & & 1 & & 1 \\
\hline 60 & & 732 & 12 & 0 & & 0 & & 1 & & 1 \\
\hline
\end{tabular}

Table 6. Estimation of availability of Engine system

\begin{tabular}{|c|c|c|c|c|c|c|c|c|c|c|}
\hline $\begin{array}{l}\text { SL. } \\
\text { NO. }\end{array}$ & MONTH & $\begin{array}{c}\text { UPTI } \\
\text { ME } \\
\text { (HOU } \\
\text { RS) }\end{array}$ & $\begin{array}{c}\text { DOW } \\
\text { N } \\
\text { TIME } \\
\text { (HOU }\end{array}$ & $\begin{array}{c}\text { NO. } \\
\text { OF } \\
\text { FAIL } \\
\text { URES }\end{array}$ & $\begin{array}{c}\text { MTB } \\
\text { F } \\
\text { (HOU } \\
\text { RS) }\end{array}$ & $\begin{array}{c}\text { HAZA } \\
\text { RD } \\
\text { RATE }\end{array}$ & $\begin{array}{c}\text { MDT } \\
\text { (HOU } \\
\text { RS) }\end{array}$ & $\mathbf{A}_{\mathrm{OP}}$ & $\begin{array}{c}\text { MTTR } \\
\text { (HOU } \\
\text { RS) }\end{array}$ & $\mathbf{A}_{\mathbf{I N}}$ \\
\hline 1 & January'0 & 720 & 24 & 0 & & & & 1 & & 1 \\
\hline 2 & & 620 & 12 & 0 & & & & 1 & & 1 \\
\hline 3 & & 576 & 144 & 0 & & & & 1 & & 1 \\
\hline 4 & & 600 & 120 & 1 & 600 & 0.0016 & 120 & 0.833 & 36 & 0.948 \\
\hline 5 & & 708 & 36 & 0 & & & & 1 & & 1 \\
\hline 6 & & 700 & 20 & 1 & 700 & 0.0014 & 20 & 0.972 & 6 & 0.991 \\
\hline 7 & & 734 & 10 & 0 & & & & 1 & & 1 \\
\hline 8 & & 734 & 10 & 0 & & & & 1 & & 1 \\
\hline 9 & & 648 & 72 & 0 & & & & 1 & & 1 \\
\hline 10 & & 734 & 10 & 0 & & & & 1 & & 1 \\
\hline 11 & & 672 & 48 & 0 & & & & 1 & & 1 \\
\hline 12 & & 670 & 24 & 0 & & & & 1 & & 1 \\
\hline 13 & January'0 & 724 & 10 & 0 & & & & 1 & & 1 \\
\hline 14 & & 686 & 10 & 0 & & & & 1 & & 1 \\
\hline 15 & & 732 & 12 & 0 & & & & 1 & & 1 \\
\hline 16 & & 638 & 82 & 0 & & & & 1 & & 1 \\
\hline 17 & & 734 & 10 & 0 & & & & 1 & & 1 \\
\hline 18 & & 710 & 10 & 0 & & & & 1 & & 1 \\
\hline 19 & & 660 & 84 & 0 & & & & 1 & & 1 \\
\hline 20 & & 710 & 10 & 0 & & & & 1 & & 1 \\
\hline 21 & & 708 & 12 & 0 & & & & 1 & & 1 \\
\hline 22 & & 744 & 0 & 0 & & & & 1 & & 1 \\
\hline 23 & & 624 & 72 & 0 & & & & 1 & & 1 \\
\hline 24 & & 734 & 10 & 0 & & & & 1 & & 1 \\
\hline 25 & January'0 & 696 & 48 & 0 & & & & 1 & & 1 \\
\hline 26 & & 600 & 72 & 0 & & & & 1 & & 1 \\
\hline 27 & & 733 & 10 & 1 & 733 & 0.0013 & 10 & 0.986 & 3 & 0.996 \\
\hline 28 & & 708 & 12 & 0 & & & & 1 & & 1 \\
\hline 29 & & 720 & 0 & 0 & & & & 1 & & 1 \\
\hline 30 & & 696 & 24 & 0 & & & & 1 & & 1 \\
\hline 31 & & 734 & 10 & 0 & & & & 1 & & 1 \\
\hline 32 & & 718 & 26 & 1 & 718 & 0.0013 & 26 & 0.964 & 7.8 & 0.989 \\
\hline 33 & & 710 & 10 & 0 & & & & 1 & & 1 \\
\hline 34 & & 672 & 72 & 0 & & & & 1 & & 1 \\
\hline 35 & & 710 & 10 & 0 & & & & 1 & & 1 \\
\hline 36 & & 744 & 0 & 0 & & & & 1 & & 1 \\
\hline 37 & January'1 & 600 & 120 & 0 & & & & 1 & & 1 \\
\hline 38 & & 600 & 48 & 0 & & & & 1 & & 1 \\
\hline 39 & & 720 & 24 & 0 & & & & 1 & & 1 \\
\hline 40 & & 576 & 144 & 0 & & & & 1 & & 1 \\
\hline 41 & & 744 & 0 & 0 & & & & 1 & & 1 \\
\hline 42 & & 696 & 24 & 0 & & & & 1 & & 1 \\
\hline 43 & & 600 & 120 & 0 & & & & 1 & & 1 \\
\hline
\end{tabular}




\begin{tabular}{|c|c|c|c|c|c|c|c|c|c|c|}
\hline 44 & & 720 & 24 & 0 & & & & 1 & & 1 \\
\hline 45 & & 720 & 24 & 0 & & & & 1 & & 1 \\
\hline 46 & & 696 & 0 & 0 & & & & 1 & & 1 \\
\hline 47 & & 672 & 24 & 0 & & & & 1 & & 1 \\
\hline 48 & & 734 & 48 & 0 & & & & 1 & & 1 \\
\hline 49 & January'1 & 732 & 12 & 0 & & & & 1 & & 1 \\
\hline 50 & & 576 & 120 & 1 & 576 & 0.0017 & 120 & 0.827 & 36 & 0.941 \\
\hline 51 & & 144 & 192 & 0 & & & & 1 & & 1 \\
\hline 52 & & 552 & 168 & 0 & & & & 1 & & 1 \\
\hline 53 & & 504 & 216 & 0 & & & & 1 & & 1 \\
\hline 54 & & 648 & 72 & 0 & & & & 1 & & 1 \\
\hline 55 & & 720 & 24 & 0 & & & & 1 & & 1 \\
\hline 56 & & 696 & 48 & 0 & & & & 1 & & 1 \\
\hline 57 & & 600 & 120 & 0 & & & & 1 & & 1 \\
\hline 58 & & 600 & 120 & 1 & 600 & 0.0016 & 120 & 0.833 & 36 & 0.943 \\
\hline 59 & & 648 & 72 & 0 & & & & 1 & & 1 \\
\hline 60 & & 732 & 12 & 0 & & & & 1 & & 1 \\
\hline
\end{tabular}

Table 6. Availability of different components of the Railway Diesel Locomotive Engine

\begin{tabular}{|c|c|c|}
\hline SL. NO. & NAME OF THE DIFFERENT COMPONENTS & AVAILABILITY \\
\hline 1 & Power pack assemblies & 0.993 \\
\hline 2 & Engine system & 0.997 \\
\hline
\end{tabular}

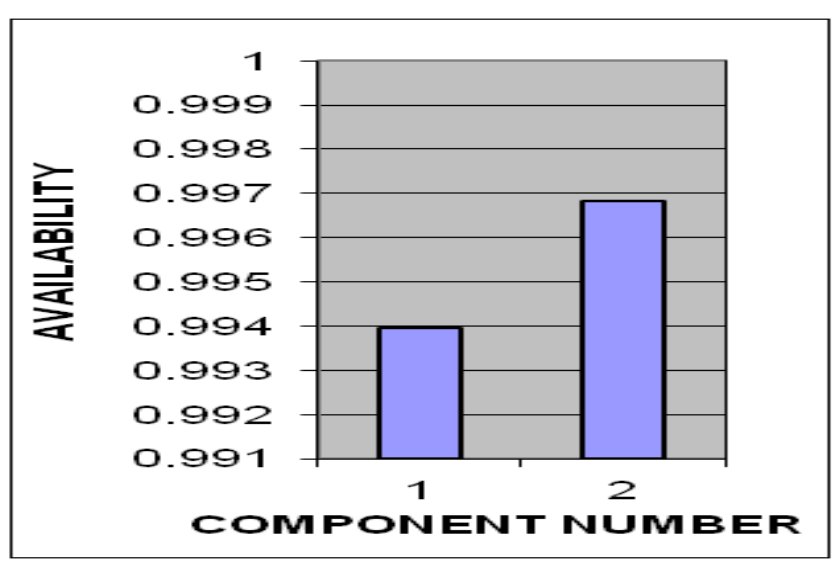

Figure 14. Availability graph for different components

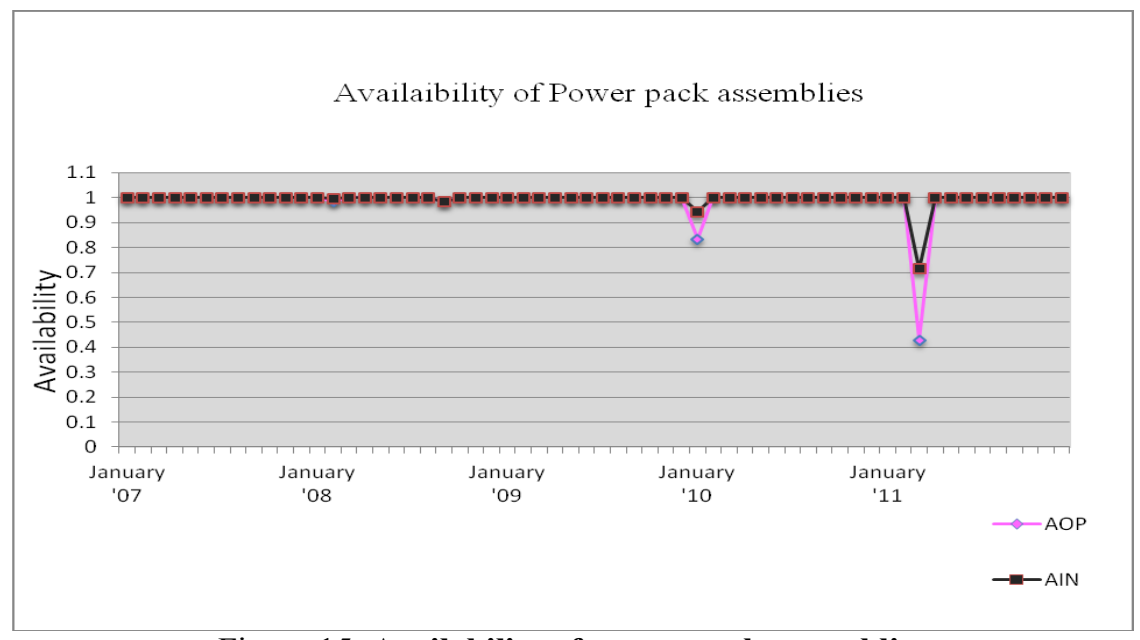

Figure 15. Availability of power pack assemblies 


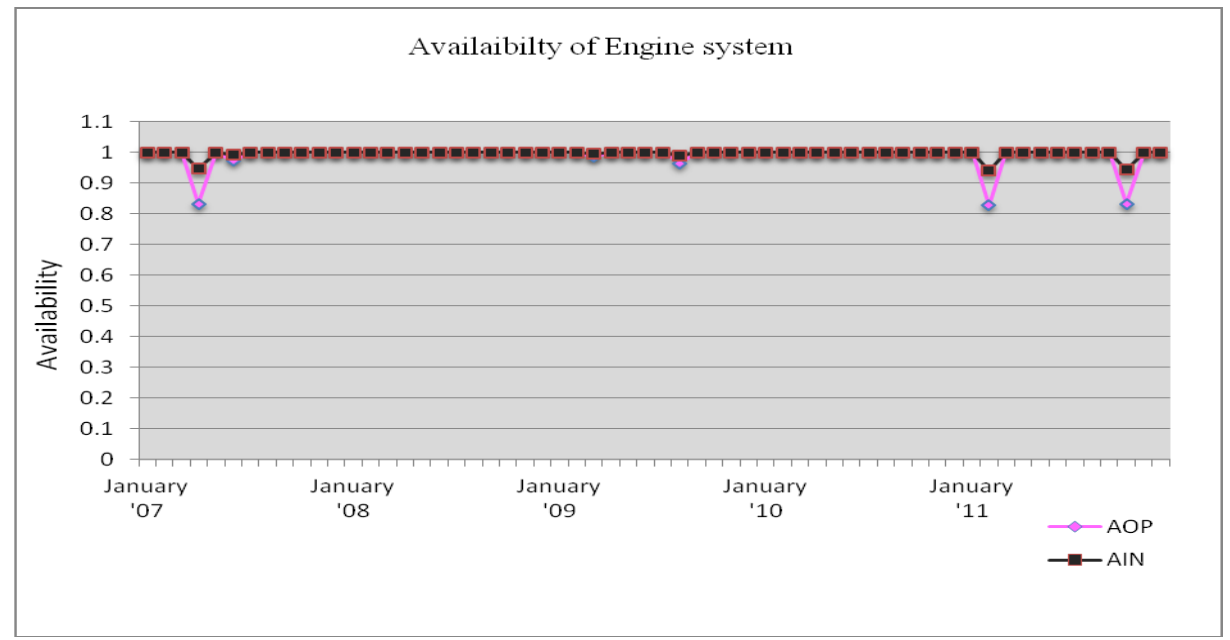

Figure 16. Availability of Engine system

\subsection{Maintenance}

\section{Development of Spares Planning and Control System}

The definition often stated maintenance as an activity carried out for any equipment to ensure its reliability to perform its functions [8].Maintenance to most people is any activity carried out on an asset in order to ensure that the asset continues to perform its intended functions or to repair any equipment that has failed or to keep the equipment running or to restore to its favorable operating condition. Over the years, many new strategies have been implemented as maintenance strategies which are intended to overcome the problems which are related to equipment breakdown. Some of the common maintenance strategies [9] are as follows:-

Table 7. Maintenance Strategy

\begin{tabular}{|c|c|c|}
\hline MAINTENANCE STRATEGY & MAINTENANCE APPROACH & SIGNIFICATION \\
\hline Corrective Maintenance & Fix it when broke & Periodic component replacement. \\
\hline Preventive Maintenance & Scheduled Maintenance & $\begin{array}{c}\text { Maintenance decision based on equipment } \\
\text { condition. }\end{array}$ \\
\hline Predictive Maintenance & Condition based Monitoring \\
\hline Proactive Maintenance & Detection of sources of failures. & $\begin{array}{c}\text { Monitoring and correcting root causes of } \\
\text { failure. }\end{array}$ \\
\hline
\end{tabular}

\subsection{Classification for selective control of spare parts inventory- ABC Analysis}

The objective of carrying out $\mathrm{ABC}$ analysis is to develop policy guidelines for selective controls of spare parts. The ABC classification of the spare parts of Railway Diesel Engine has been performed on the basis of their annual consumption in rupees. The entire procedure for making ABC analysis is summarized in the following steps:

i) Annual consumptions in rupees have been calculated for each spare part.

ii) The sorting of spare parts has been performed on the basis of annual consumptions in rupees in descending order.

iii) Cumulative annual usage and cumulative $\%$ usage are estimated which are shown in Table 8 . The parts are categorized considering the cumulative $\%$ usage.

iv) The Pareto chart figure 17 is obtained for the spare parts by plotting cumulative percentage usage against the ranks of the parts in descending order to visualize the $\mathrm{ABC}$ categories.

Table 8. ABC Analysis of the spare parts

\begin{tabular}{|c|c|c|c|c|c|}
\hline RANK & SPARE PART & $\begin{array}{c}\text { ANNUAL USAGE } \\
\text { [IN RUPEES.] }\end{array}$ & $\begin{array}{c}\text { CUMULATIVE } \\
\text { ANNUAL USAGE }\end{array}$ & $\begin{array}{c}\text { CUMULATIVE } \\
\text { \% USAGE }\end{array}$ & CATEGORY \\
\hline 1 & Power pack & $82,15,810.90$ & 18633720 & 48.67127014 & $\mathrm{~A}$ \\
\hline 2 & Engine system & $68,45,035.00$ & 25478755 & 66.55049917 & $\mathrm{~B}$ \\
\hline
\end{tabular}




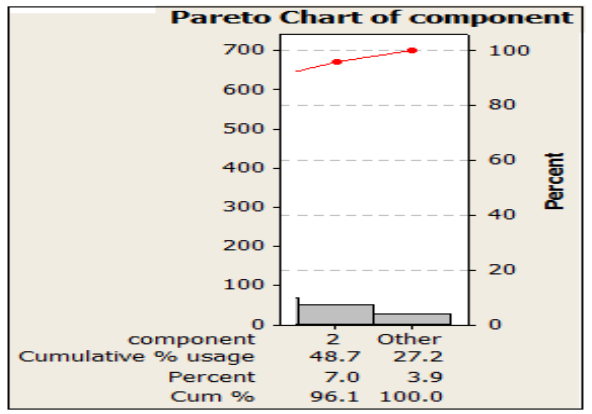

Figure 17.Paratoo chart

\subsection{Reliability Estimation}

\section{Results \& Discussions}

Reliability estimation of the different components of the Locomotive Engine of Railways provides the values of shape parameters as well as reliability (Table 9) which focuses on the performance of the components of the Locomotive Engine during the period of January, 2007 to December, 2011.

Table 9. Reliability of the Railway Locomotive Engine components

\begin{tabular}{|c|c|c|c|c|c|}
\hline $\begin{array}{c}\text { SL. } \\
\text { NO. }\end{array}$ & $\begin{array}{c}\text { NAME OF THE DIFFERENT } \\
\text { COMPONENTS }\end{array}$ & $\begin{array}{c}\text { SHAPE PARAMETER } \\
\text { (B) } \\
\text { (FROM WEIBULL } \\
\text { PLOT) }\end{array}$ & $\begin{array}{c}\text { MEAN } \\
\text { OPERATING } \\
\text { HOUR } \\
\text { (IN HOURS) }\end{array}$ & $\begin{array}{c}\text { FAILURE } \\
\text { PROBABILI } \\
\text { TY } \\
\text { FAILURE } \\
\text { PROBABILI } \\
\text { TY }\end{array}$ \\
\hline 1 & Power pack assemblies & 5.299 & 644.407 & 64.476 & 35.523 \\
\hline 2 & Engine system & 6.187 & 657.303 & 65.878 & 34.121 \\
\hline
\end{tabular}

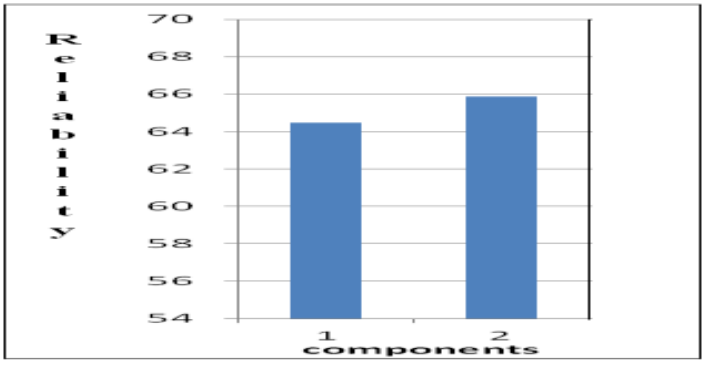

Figure 18. Reliability of different components for Locomotive Engine

From Fig.18, it is found that the estimated Reliability of the different components of the "Railway Diesel Locomotive Engine" is in the range of 59\% to $68 \%$. The reliability of the Transmission cables the maximum (67.998\%) whereas the minimum (59.9987\%) reliability is for the vehicle and structure.

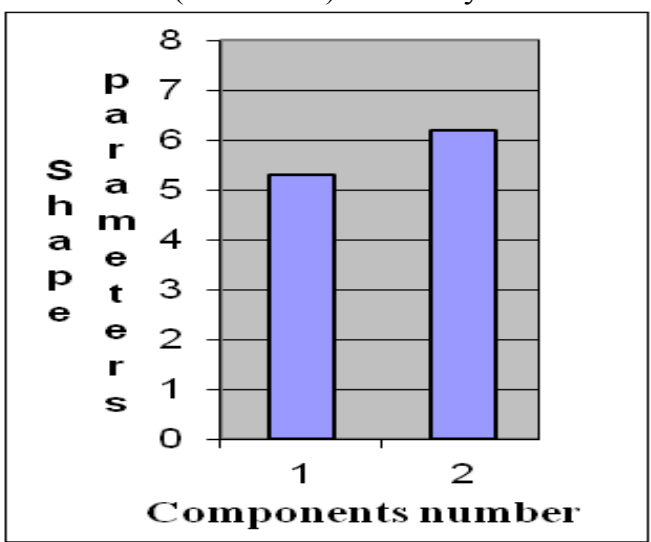

Figure 19. Shape parameter of different components 
Weibull shape parameter is the indicative of the possible failure mechanism and the causes of failures of any component. Table 10 shows the classification of shape parameters according to their values indicating possible failure mechanism and cause of failure.

Table 10. Classification of shape parameter

\begin{tabular}{|c|c|c|}
\hline SHAPE PARAMETER VALUE & POSSIBLE FAILURE MECHANISM & CAUSES OF FAILURE \\
\hline$\beta>2$ & Age related pattern & $\begin{array}{c}\text { Accelerated wear and tear of } \\
\text { components. }\end{array}$ \\
\hline$\beta \approx 1$ & Time independent pattern & $\begin{array}{c}\text { Process error, design fault, mal } \\
\text { operation }\end{array}$ \\
\hline$\beta<1$ & Early failure & $\begin{array}{c}\text { Manufacturing failure, and } \\
\text { reconditioning fault. }\end{array}$ \\
\hline
\end{tabular}

The values of the shape parameters of the different components of the Railway Diesel Locomotive engine are given in Table 9 \& Fig.19. It is evident that the possible failure mechanism of various components falls into the category of age related pattern and failures occur due to accelerated wear and tear of components (Table 10).

\subsection{Availability of Different Components of the Railway Locomotive Engine}

As per the definition of operational availability, the availability of different components of the Railway Diesel Locomotive Engine is calculated for a particular month starting from January, 2007 to December, 2011. After that the average operational availability of each component is calculated. A detailed average operational availability of different components of the Railway Diesel Locomotive Engine is given Table 11 and Fig.20.

Table 11. Estimated Operational Availability of the Railway Diesel Locomotive Engine components

\begin{tabular}{|c|c|c|}
\hline SL. NO. & NAME OF THE DIFFERENT COMPONENTS & $\begin{array}{l}\text { AVERAGE OPERATIONAL } \\
\text { AVAILABILITY }\end{array}$ \\
\hline 1 & Power pack assemblies & 0.997 \\
\hline 2 & Engine system & 0.990 \\
\hline
\end{tabular}

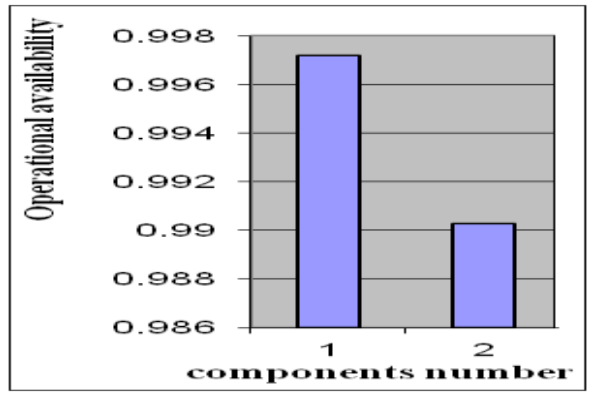

Figure 20. Operational availability of different components

Considering operational availability and inherent availability vs. time period for different components of the Railway Diesel Locomotive Engine (Fig.15 to16) show the availability patterns of Railway Diesel Engine during the period under study (January, 2007 to December, 2011).

Figure.15: shows that the power pack assemblies undergoes preventive maintenance and overhauling for shorter period during the months of December 2009 to January 2010, and December 2010 to February 2011 as both the inherent and operational availability are coinciding with each other.

Figure.16: shows that the engine system comes under preventive maintenance and overhauling during the months of April2007 to May 2007, and January 2011 to February2011 and September2011 to October2011 as both the inherent and operational availability are coinciding with each other.

\subsection{Analyses of the Major Causes of Failures and Recommendations for Their Remedies}

After analyzing the failures of the Railway Diesel Locomotive Engine components, the major causes of failures include careless and inexperienced handling, improper and excessive loading, environmental, careless operation, degradation etc 


\subsection{Proposed Maintenance Schedule}

It is true that the failures of the engine parts cannot be fully prevented i.e. $100 \%$ availability cannot be achieved, but the probability of failure and frequency of failures, and thus risk can be checked or lowered through proper condition monitoring of the Railway Diesel Locomotive Engine components.

Following are the causes and the recommended preventive measures to be taken for the major components of the engine.

Table 12.Power pack assemblies' failures

\begin{tabular}{|c|c|}
\hline Causes & Corrective actions \\
\hline 61 Liner chrome layer peeled off & Letter sent to DMW for necessary corrective action. \\
\hline Cylinder head crack & Letter sent to dy. cme/jmp for farther preventive action in POH \\
\hline 81 Cam shaft sheared in two pieces & Welding of cam lobe cam lobes should be avoided. \\
\hline Cylinder. Head dummy plug thrown out. & $\begin{array}{c}\text { Dummy plug should be checked during OVH. lock tight } 609 \text { to } \\
\text { be applied if found loose }\end{array}$ \\
\hline Cylinder. Head valve broken & Replace \\
\hline
\end{tabular}

Table 13.Engine system

\begin{tabular}{|c|c|}
\hline CAUSES & CORRECTIVE ACTIONS \\
\hline Flexible hose burst.(a/cooler)01 & $\begin{array}{c}\text { After cooler inlet and out let hose should be changed during m- } \\
12 \text { and above schedule in case of twin a/cooler }\end{array}$ \\
\hline Lube oil pump defective-01 & $\begin{array}{c}\text { Instruction has been given that, lube oil pump should be OVH } \\
\text { during m-48 schedule }\end{array}$ \\
\hline Fuel oil solid t-jumper broken.-1 & $\begin{array}{c}\text { Firm has been advised for quality control of material. } \\
\text { DPT testing should be done before fitment }\end{array}$ \\
\hline
\end{tabular}

\section{Conclusion}

This study has focused mainly on the estimation of the reliability and availability of a specific Railway Locomotive Engine along with maintainability aspects.

The collection of the past data is the most vital precondition to carry out such analysis. The initial stage of the present study has revolved around the collection of well defined data regarding the breakdowns and maintenance of the Engine.

It has been found that worker inefficiency, overloading, degradation of the system components with time are mainly the contributing factors for the failures of Railway Diesel Locomotive Engine.

.From the Reliability prediction of the engine components it was found that the reliability of the components ranging from $59 \%$ to $68 \%$ where maximum reliability found in case of transmission cable $(67.998 \%)$ and minimum reliability found in case of vehicle and structure (59\%). As the maximum systems of the Engine are found to be moderate Reliability and to upgrade its maintenance process of the Locomotive Engine.

The availability patterns describe the performance of the Engine. The plant is having no such correct spare parts provisioning system for a cost effective and timely managed maintenance practice. Whenever any breakdown occurs, the maintenance department places an indent on the requirements for a particular spare part to the store, if the spare is available in the store they supply it to maintenance department and if not, then order is placed to the purchase department as a result maintenance process gets delayed. A spare parts provisioning model has been introduced to estimate the safety stock. In-depth and continuous study it is required to analyzing the effects of the preventive maintenance action for the Railway Locomotive Engine components, controlling and monitoring of spare parts on reliability aspects.

\section{References}

[1]. E.A. Elsayed, Reliability Engineering (Addison Wesley Longman, 1996).

[2]. B. Bhadury and S.K. Basu, Tero-technology: Reliability Engineering and Maintenance Management-Asian Book Private Limited, 2003, Edition I.

[3]. L.S. Srinath, Reliability Engineering (East West Press, Edition IV, 2005).

[4]. I. Ushakov, Reliability: past, present, future, Recent Advances in Reliability Theory: Methodology, Practice, and Interface, Birkhauser, Boston, 2000, pp. 3-14.

[5]. P. Jager and B. Bertsche, A new approach to gathering Failure Behavior Information about Mechanical Components based on Expert Knowledge, Proc. Ann Reliability \& Maintainability Symp. January-2004, PP 90-95.

[6]. Kales Paul, Reliability for Technology, Engineering and Management (Prentice Hall, 1998).

[7]. D. J.Smith, Reliability Engineering (Pitman Publishing, 1972).

[8]. Mitchell Leslie, Preventive maintenance and RCM, IEEE, 2002

[9]. W. Nelson, Weibull prediction of a future number of failures, Quality Reliability Engg. Int., vol.16, 2000 , pp 23-26. 